\title{
Penetrating eye injuries in road traffic accidents
}

\author{
B. C. K. PATEL \& L. H. MORGAN \\ Department of Anaesthesiology, Manchester Royal Eye Hospital, Manchester, England
}

\section{SUMMARY}

A review of all penetrating eye injuries treated by the Manchester Eye Hospital over four years (1 February 1982-31 January 1986) was undertaken. One hundred and ninety-six penetrating eye injuries were seen, of which $16(8.2 \%)$ were due to road traffic accidents. Eight patients (nine eyes) were seen in the 12 months prior to the introduction of the seat-belt legislation on 1 February 1983. None of these patients was wearing a seat-belt whereas two of the eight patients (10 eyes) seen after the seat-belt legislation were. Both these patients suffered severe visual loss due to intraocular glass from shattered windscreens. Three patients had bilateral penetrating eye injuries, one before and two after the seat-belt legislation. Two of the nine eyes involved prior to the legislation and three of the 10 eyes after the legislation had an eventual visual acuity of $6 / 12$ or better. In the majority of patients, failure to wear seat-belts or defective use is to blame. Flying glass from shattered toughened windscreens is a preventable danger. Nine of the 16 patients were first seen in the general accident and emergency department and, of these, seven did not have visual acuities recorded prior to referral to an ophthalmologist. The importance of measurement of the visual acuity and detection of an afferent pupillary defect is stressed based on these findings.

\section{INTRODUCTION}

Road traffic accidents are an important cause of perforating eye injury with resulting visual loss and cosmetic disability. On 1 February 1983, the compulsory use of seatbelts by front-seat occupants of cars was introducted to the United Kingdom. Reports indicate a significant reduction in fatalities and injuries from road traffic accidents during the first year after the seat belt legislation (Rutherford $e t$ al., 1985). A significant decrease in ocular injuries in the 6 months after the introduction of the seat-belt legislation was also noted (Vernon \& Yorston, 1984). Road traffic accident victims who 
suffer penetrating eye injuries often have other severe injuries as well and are often first seen in the general accident and emergency department. The authors set up a retrospective study which examined all penetrating eye injuries during the year $\frac{3}{\infty}$ immediately before the seat-belt legislation and the 3 years following it to assess the ? mode of presentation of injuries due to road traffic accidents, the initial assessment and $\underset{\vec{F}}{\vec{*}}$ management of these patients, and the longer-term effect of the seat-belt legislation.

\section{METHODS AND MATERIALS}

The Manchester Royal Eye hospital, Manchester, England, is a 149-bed regional ophthalmic centre serving a population of about one million and has an annual accident $\stackrel{\circ}{\circ}$ and emergency department attendance of $\mathbf{4 0 0 0 0}$ patients. The authors examined the 3 records of all patients treated for penetrating eye injuries between 1 February 1982 and 31 January 1986. Where injury resulted from a road traffic accident, details of initial $\vec{i}$ presentation (to a general accident and emergency department or an eye casualty) and of $\vec{\circ}$ the initial management were recorded. Details of the injuries, patient's age and sex, $\stackrel{5}{\longrightarrow}$ seat-belt compliance, position in the vehicle and visual recovery were also recorded.

\section{RESULTS}

One hundred and ninety-six patients with penetrating eye injuries were seen between $\frac{a}{3}$ February 1982 and 31 January 1986 . Of these, 16 (10 males and six females) were due to road traffic accidents (Table 1 ). Nine patients were first seen in a general accident and 8 emergency department with the rest presenting directly to the eye casualty department. $\overrightarrow{\vec{O}}$ For the nine patients, the period between presentation and referral to the eye 3 department ranged from $30 \mathrm{~min}$ to 6 days. Seven of the nine patients did not have visual acuities recorded at any stage prior to referral to the ophthalmologist. None of the patients were recorded as being unconcious at the time of presentation to the emergency department.

There was a fall in the number of penetrating eye injuries in the 3 years following the introduction of the seat-belt legislation but the small number does not allow statistical analysis. The eight patients seen prior to the legislation (1982) were front-seat

Table 1 Distribution of 196 penetrating eye injuries by year and cause

\begin{tabular}{|c|c|c|c|c|}
\hline & \multicolumn{4}{|c|}{ Year } \\
\hline & $1982-83$ & $1983-84$ & $1984-85$ & $1985-86$ \\
\hline Road traffic accidents & 8 & 2 & 2 & 4 \\
\hline Others & 50 & 52 & 41 & 37 \\
\hline Total & 58 & 54 & 43 & 41 \\
\hline
\end{tabular}


occupants, five drivers and three passengers. There were no seat-belt wearers in this group. Of the eight patients in the post-legislation group (1983-86), one had not actually slotted the belt and one was a back-seat passenger. Two were wearing a seatbelt and both had intraocular glass with severe visual loss. Table 2 lists the full details of all the patients. Three bilateral perforations were treated and, of these, two occurred after the seat-belt legislation. Twelve $(75 \%)$ of the 16 patients were under the age of 40 years and males were more commonly injured than females. Two of the nine eyes in the pre-legislation period and three of the 10 eyes in the post-legislation period retained vision of $6 / 12$ or better. Patients number 16 was a back-seat passenger who was thrown through the windscreen and had intraocular glass.

\section{DISCUSSION}

Road traffic accidents are a major cause of physical handicap in the young adult population and penetrating eye injuries are a significant cause of visual loss in this group. Impact of the victim's head against a shattered windscreen is the commonest mechanism of injury leading to perforation of the eye (Blake et al., 1983). This mode of injury is preventable by seat-belt use and on 1 February 1983 compulsory front seatbelt was introduced in the United Kingdom.

Of penetrating eye injuries, $30.2 \%$ were found to be due to road traffic accidents in Northern Ireland from 1967 to 1976 (Canavan et al., 1980). The present authors' figure was $14 \%$ for the year prior to the introduction of the seat-belt legislation and $6 \%$ for the 3 years after its introduction. The reduction in penetrating eye injuries noted over the 3

Table 2 Details of penetrating eye injuries in road traffic accidents

\begin{tabular}{|c|c|c|c|c|c|c|}
\hline Year & Patient & Sex & Age & Eye & Eventual VA & Details \\
\hline \multirow[t]{9}{*}{$1982-83$} & 1 & $\mathbf{F}$ & 18 & $\mathbf{L}$ & PL & Driver. No seat-belt \\
\hline & 2 & $\mathbf{M}$ & 46 & $\mathbf{R}$ & PL & Passenger. No seat-belt \\
\hline & 3 & $\mathbf{M}$ & 19 & L & $6 / 24$ & Driver. No seat-belt \\
\hline & 4 & $\mathbf{M}$ & 31 & $\mathbf{R}$ & $6 / 18$ & Passenger. No seat-belt \\
\hline & 5 & $\mathbf{M}$ & 28 & $\mathbf{R}$ & $6 / 6$ & Driver. No seat-belt \\
\hline & & & & L & $6 / 60$ & \\
\hline & 6 & $\mathbf{F}$ & 24 & $\mathbf{R}$ & $6 / 9$ & Passenger. No seat-belt \\
\hline & 7 & $\mathbf{M}$ & 25 & $\mathbf{R}$ & $6 / 60$ & Driver. No seat-belt \\
\hline & 8 & $\mathbf{M}$ & 32 & L & HM & Driver. No seat-belt \\
\hline \multirow[t]{3}{*}{$1983-84$} & 9 & $\mathbf{M}$ & 19 & $\mathbf{R}$ & $6 / 9$ & Driver. No seat-belt \\
\hline & & & & $\mathbf{L}$ & Enucleation & \\
\hline & 10 & $\mathbf{M}$ & 23 & $\mathbf{R}$ & PL & Passenger. No seat-belt \\
\hline \multirow[t]{3}{*}{$1984-85$} & 11 & $\mathbf{F}$ & 23 & $\mathbf{R}$ & $6 / 60$ & Driver. No seat-belt \\
\hline & & & & $\mathbf{L}$ & $6 / 6$ & \\
\hline & 12 & $\mathbf{F}$ & 17 & $\mathbf{R}$ & $6 / 6$ & Driver. Seat-belt not slotted in \\
\hline \multirow[t]{4}{*}{$1985-86$} & 13 & $\mathbf{M}$ & 63 & $\mathbf{R}$ & PL & Driver. Wearing seat-belt \\
\hline & 14 & $\mathbf{M}$ & 50 & $\mathbf{L}$ & HM & Passenger. No seat-belt \\
\hline & 15 & $\mathbf{F}$ & 28 & $\mathbf{L}$ & $6 / 60$ & Passenger. Wearing seat-belt \\
\hline & 16 & $\mathbf{F}$ & 65 & $\mathbf{L}$ & Enucleation & Rear-seat passenger. \\
\hline
\end{tabular}


years following the introduction of the legislation corresponds with the $73 \%$ reduction in the first year post-legislation reported by Hall et al. (1985) and 83.3\% by Rutherfordo et al. (1985). The use of seat belts by front-seat occupants was estimated at $92 \%$ during 3 the first year of legislation compared with $25 \%$ during 1982 (Rutherford et al., 1985).

Although the risk of penetrating eye injury has been greatly reduced by the introduction of the seat-belt legislation, the expected level of visual recovery iso unchanged. The majority of patients suffer from severe visual loss and only two of the $\frac{\overline{0}}{\overline{0}}$. nine eyes prior to the legislation and three of the 10 eyes after the legislation achieved $\frac{\omega_{\bar{N}}^{\circ}}{}$ vision of $6 / 12$ or better. It is, however, important to note that only two of the eight occupants injured after the legislation were wearing seat-belts and one of the eight priores to the legislation were doing so. All three patients who suffered bilateral penetrating $\overrightarrow{0}$ ocular injuries were in the driving seat and not wearing seat-belts. Both the occupants $\vec{\omega}$ wearing seat-belts (patients 13 and 15) had intraocular glass and suffered severe visua loss. Ophthalmoscopic examination of the eye, assessment of visual acuity and determi- -3 . nation of an afferent pupillary defect must be incorporated in the examination of all roadir traffic accident victims in whom eye injury could possibly have occurred. This iș important as the initial visual acuity is known to be a very important visual prognostic $\overrightarrow{0}$ factor (De Juan et al., 1983). These simple examinations may also help to detect penetrating eye injuries earlier in patients who may have other severe injuries.

The danger of flying windscreen glass as a cause of ocular perforation in spite of seat belt wear was emphasized by Blake et al. (1983). Despite observing the seat-belt law, two patients in this study suffered severe ocular injury from flying glass. The्रुe⿻ observations support the findings of MacKay (1975) that use of laminated instead toughened windscreens would further reduce the incidence of facial and ocular injuries. Laminated glass, which has a layer of plastic between two layers of tempered glass haștaㅇ high penetration resistance and does not shatter like the toughened glass currently used in most European vehicles. Laminated glass has been used as standard in all cars in the USA for some 40 years and a similar regulation in the United Kingdom is strongly recommended.

The finding of only two $(11 \%)$ patients who were wearing seat-belts and suffered penetrating eye injuries out of the 18 stresses the importance of seat-belt use and injuries continue largely due to their non-use or faulty use. Injuries due to flying glasș may be reduced by the compulsory use of laminated glass in all new vehicles.

\section{REFERENCES}

Blake J., Kelly G., Fahey C. \& Khan M. A. (1983) Eye injuries in road traffic accidents. Irish Medical fourna 76, $120-4$.

Canavan Y. M., O'Flaherty M. J., Archer D. B. \& Elwood J. H. (1980) A ten-year survey of eye injuries in Northern Ireland. British fournal of Ophthalmology 64, 618-25.

De Juan E., Sternberg P. \& Michels R. G. (1983) Penetrating ocular injuries: types of injuries and visuab results. Ophthalmology $90,1318-22$.

Hall N. F., Denning A. M., Elkington A. R. \& Cooper P. J. (1985) The eye and the seat-belt in Wessex British fournal of Ophthalmology 69, 317-9.

MacKay G. M. (1975) Incidence of trauma to the eyes of car occupants. Transactions of the Ophthalmologicalo Societies of the United Kingdom 95, 311-4. 
Rutherford W. H., Greenfield T., Hayes H. R. M. \& Nelson J. K. (1985) The medical effects of the seat-belt legislation in the United Kingdom. Department of Health and Social Security Office of the Chief Scientist: Research report no. 13. London, HMSO.

Vernon S. A. \& Yorston D. B. (1984) Incidence of ocular injuries from road traffic accidents after introduction of seat-belt legislation. Fournal of the Royal Society of Medicine 77, 198-200. 